How to cite this article:

Jamil, N., Ramli, I., \& Ardi, N. (2019). Formant characteristics of Malay vowels of Perlis, Kelantan and Terengganu. Journal of Information and Communication Technology, 18(4), 529544.

\title{
FORMANT CHARACTERISTICS OF MALAY VOWELS OF PERLIS, KELANTAN AND TERENGGANU
}

\author{
${ }^{1}$ Nursuriati Jamil, ${ }^{1}$ Izzad Ramli \& ${ }^{2}$ Norizah Ardi \\ ${ }^{I}$ Faculty of Computer and Mathematical Sciences, \\ Universiti Teknologi MARA, Malaysia, \\ ${ }^{2}$ Academy of Language Studies, Universiti Teknologi MARA, Malaysia, \\ norizah@salam.uitm.edu.my; lizajamil@computer.org; \\ zadzed89@yahoo.com
}

\begin{abstract}
The pronunciation of Malay vowels are taught according to the International Phonetic Association transcription sound chart. The documentation for pronunciations are conducted by describing and distinguishing the vowel's sound through impressionistic. In the last five years, several studies were carried out to quantify the standard Malay vowels pronunciation using formant frequencies. However, only one work was identified that measures Malay vowels using formant frequencies for the Kedah district. Nonetheless, there were contradiction in some of the findings as the spoken vowels were extracted from a read speech, that may not be representative of the natural dialect. Therefore, this paper investigated the Malay vowels variations from three districts (Perlis, Kelantan, and Terengganu) using spontaneous speeches acquired in a natural setting. Eight (8) Malay vowels were collected from local males and females residing in Perlis, Kelantan, and Terengganu. Four formant frequencies (F1-F4) were measured from the vowels extracted from the spontaneous speeches of the locals. Further analysis on the first and second formant suggest that the Malay vowels of Terengganu and Kelantan have a broader range of formants that are located in approximately the same position in the mouth. However, the vowels of the Perlis dialects were closely positioned in a narrower region of the mouth. A Malay vowel diagram was
\end{abstract}


plotted that can be used for future reference in research and as an educational tool for language learning. Furthermore, Kelantan and Terengganu dialects are shown to be similar based on the first and second formants.

Keywords: Formant frequencies, Malay dialect, vowel diagram, vowel recognition.

\section{INTRODUCTION}

The Malay language is described in the Encyclopedia Britannica (2018) as a branch of the Austronesian language family that is spoken by more than 33 million people from countries such as Malaysia, Indonesia, Southern Thailand, Singapore and Brunei, as reported by O'grady and Archibald (2015). The Malay language is the national language of Malaysia, whereby English is the second language of the country. As in many other countries, the Malay language and dialects varies according to the geographical and district locations. As stated by Collins (1989), a dialect is defined as a particular language that has diverse elements in vocabulary, grammar, and pronunciation. Wardhaugh (2011) suggested that dialect is a subordinate variety of a language. Malay dialects in Malaysia, as stated by Omar (1985) are generally divided into 12 dialect district; nine Malay dialects in Peninsular Malaysia and three in Sabah and Sarawak, indicated by Collins and Bahar (2000). The nine (9) districts in peninsular Malaysia are Kedah, Perak, Selangor, Negeri Sembilan, Melaka, Johor, Pahang, Terengganu, and Kelantan. Asmah (1988) further divided the Malay dialects of Peninsular Malaysia into four main groups, which are: 1) the north-western group that include Kedah, Perlis, and Penang, 2) the northeastern group that comprises of Kelantan Malay, 3) the eastern group of Terengganu Malay, and 4) the southern group that consist of Johor, Melaka, Pahang, Selangor, and Perak. Collins (1989) further stated that the dialect in Perlis and Penang have a close relationship to the Kedah dialect, and was subsequently categorized as the same dialect.

Thus far, there is only one work conducted by Afiqah (2017) that compares the variations of dialect pronunciations between geographical and district areas. The study compared Kedah Malay vowels with standard Malay vowels, based on the acoustic analysis of the formants. The speakers for the Kedah dialects were five females from the same district in Kedah, while the standard Malay vowels were acquired from speakers in the Klang Valley. The speakers from Kedah were asked to read a set of sentences naturally in their respective 
Kedah dialect, while the speakers from Klang Valley were asked to read the same sentences in standard Malay. The recordings were transcribed, and the first (F1) and second (F2) formant of the vowels were extracted using Praat. The findings affirmed Asmah's (1988) work and concluded that the Kedah Malay dialect is comprised of eight vowels $/ \mathrm{a} /, / \mathrm{e} /, / \mathrm{i} /, / \mathrm{o} /, / \mathrm{u} /, / \mathrm{\partial} /, / \mathrm{o} /$, and $/ \varepsilon /$. However, regarding vowel location, there are disagreements between Afiqah (2017), Yusuf (2013) and Teoh (1994). The vowel /a/ is positioned at halfclose, central position in Yusuf (2013) and Teoh (1994). On the other hand, Afiqah (2017) placed the vowel /a/ at open, front position. Afiqah (2017) deduced that it is possible that the participants do not differentiate between /a/ and /a/ in Kedah Malay, as both vowels sound almost similar to each other. Afiqah (2017) further concluded that the standard Malay vowels /a/, /e/, /ə/, $/ \mathrm{i} /, / \mathrm{o} /$ and $/ \mathrm{u} /$ share similar acoustic properties with the Kedah dialect. The similarity is attributed to the way speakers read the sentence. The speakers were asked to read the sentences in Kedah Malay, however, they may have read it based on the way it is spelled. In addition, the study proposed that further recordings should be collected to obtain a realistic representation of the spoken dialects. Therefore, this paper examines the vowels pronunciation of spontaneous speeches based on formant frequencies for the dialects of Perlis (north-western), Kelantan (north-eastern) and Terengganu (eastern). These three districts were chosen because the dialects spoken in these districts are more conspicuous than the dialects in the southern districts, which are closer to the standard Malay dialect. The methodology of this paper is carried out as follows: 1) Eight Malay vowels from the spontaneous speeches of Perlis, Kelantan, and Terengganu were collected and documented using technology instrument, 2) The Malay vowel diagram comprising of Kelantan, Perlis, and Terengganu districts was introduced, and 3) Similarity measurement of Kelantan, Perlis and Terengganu dialects based on the first and second formants were conducted.

\section{RELATED WORK}

Various studies on the acoustic properties of the Malay language vowels have been conducted in the last decade. The studies by Zourmand, Mirhassani, Ting, Bux, Ng, Bilgen, and Jalaludin (2014), Ting, Zourmand, Chia, Yong, and Abdul Hamid (2012a), Ting, Chia, Manap, Ho, Tiu, and Abdul Hamid (2012b), Ting, Chia, Kim, Sim, and Abdul Hamid (2011a), and Ting, Chia, Abdul Hamid, and Mukari, (2011b) investigated six standard Malay vowels, /a/, /e/, /ə/, /i/, /o/ and $/ \mathrm{u} /$ acquired from Malaysian Malay or/and Chinese speakers. Ting et al. 
(2011a) explored the use of the vocal's fundamental frequency in the speech production of the six Malay vowels from Malaysian Chinese young adults. The results concluded that the fundamental frequencies of the Malaysian Chinese females had a significantly higher $\mathrm{F}_{0}$ than Malaysian Chinese males, in all six vowels. However, there is no significant difference in $\mathrm{F}_{0}$ across all vowels for each gender. Ting et al. (2011b) extended the research on Malaysian Malay young adults by extracting the $\mathrm{F}_{0}$ and perturbation measures from six sustained Malay vowels. The paper concluded that there was no significant difference between $\mathrm{F}_{0}$ and perturbation measures in all vowels. The Malay females had a higher $\mathrm{F}_{0}$ compared to Malay males, but no significant difference was found for perturbation measures across both genders. However, a comparison study on multiethnic speakers showed that $\mathrm{F}_{0}$ varies between Malaysian Malay and the other ethnic groups. The following year, Ting et al. (2012a) explored the use of four formant frequencies to identify the acoustical differences of the speech production across age groups and gender. By analyzing six sustained vowels from Malay children aged between 7 and 12 years old, the results showed that the formant frequencies of the females are generally higher than the males. However, there is no significant difference in the formant frequencies of most vowels across age groups. Ting et al. (2012) further explored the extraction of the fundamental frequency $\left(\mathrm{F}_{0}\right)$ and perturbation measures for the six vowels across age groups and gender. The results showed that there was no significant difference for $\mathrm{F}_{0}$ between the vowels for both males and females. However, there was a significant difference across the age groups. The perturbation measures had shown no significant difference across the age groups or gender. Although adequate work has been conducted on the standard Malay vowels, research on the acoustic properties of vowels in Malay dialects are still limited.

\section{METHOD}

This section presents the description of subjects, details on data collection, speech pre-processing, and extraction of formant frequencies.

\section{Subjects}

The subjects are all native Malay speakers from the states of Kelantan, Terengganu, and Perlis. They have been staying in the same districts throughout their lives, and their daily conversations with family, friends, relatives, and neighbours have been conducted in their respective dialects. At the time of recording, all subjects were in good health, and had a complete articulatory tool with no history of speech disorder. For this paper, the subjects were comprised of three males and three females that are aged between 40 to 60 years old. 


\section{Equipments and Procedures of Data Collection}

The recording of the subjects was conducted in an open, outdoor environment, instead of a controlled enclosed environment that was implemented in previous research, including Afiqah (2017). A natural setting was necessary to ensure that the spoken speech was spontaneously uttered with dialects. The conversations were conducted at the places where the subjects felt most comfortable, such as at their home, in a coffee shop or at the market. A Sony ICD-TX650 16GB slim digital voice recorder which responses to $95-20000 \mathrm{~Hz}$ and battery life for recording up to 12 hours was used to record the spontaneous conversations. The recorder is super slim, compact and lightweight for excellent recording quality and comfortable to be attached to the human body. The length of the conversations varied from 1 to 2 hours, and the recording of the speech from all six subjects was completed within a week. The recordings were then preprocessed, before vowel feature extraction.

\section{Speech Pre-Processing}

The collection of the spoken words were pre-processed to remove artifacts during the recording sessions. The sampling frequency used was $16 \mathrm{kHz}$ in mono channel with a 16-bit resolution. Framing was done by blocking the collected speech signals into frames of $N$ samples. In this paper, a frame length of 20ms was used (Ikkunointi, 2016) with the adjacent frames separated and shifted by $10 \mathrm{~ms}$ (Ikkunointi, 2016). Then, windowing was applied to minimize the signal discontinuities at the beginning and end of each frame. This method pre-multiplied the signal with a window that smoothly decreased to zero at the start and end of each frame. Hanning window was chosen to be applied to the frames as it produces smoother and accurate signals (Podder, Zaman, \& Haque, 2014) compared to Hamming or Blackman functions. When the recording was conducted in the open and outdoor environment, there was a substantial amount of interfering signals and environmental noise. Thus, filtering was employed to suppress the artifacts. High pass filtering was done using Audacity with different cut-off values, depending on the background noise. The words and vowels are annotated manually from the spoken speech using an interactive speech analysis tool, known as Praat (Boersma, David \& Heuven, 2015). Figure 1 illustrates the transcription of the speech words /ape/, /apo/, and /apobile/ for the vowel /a/. The manual annotation of the vowels waveform from the words was based on the processes provided by Praat's guidelines. The criteria that was considered to identify the start and end of a vowels are as follows: 1) dramatic change in amplitude in the waveform, 2) change and loss of the energy in the formant, and 3) the onset of aperiodicity. A linguistic expert had made the selection of the phonetic symbol provided by the IPA to represent the vowels. A total of 536 vowels (i.e. 209 vowels 
of Kelantan dialects, 183 vowels of Terengganu dialects, and 144 vowels of Perlis dialects) for all three districts were extracted from the spoken words, and was used to document the vowels pronunciations. The duration of all the vowels was $311.84 \mathrm{~s}$. The details of the dialect vowels based on each district is recorded in Table 1.

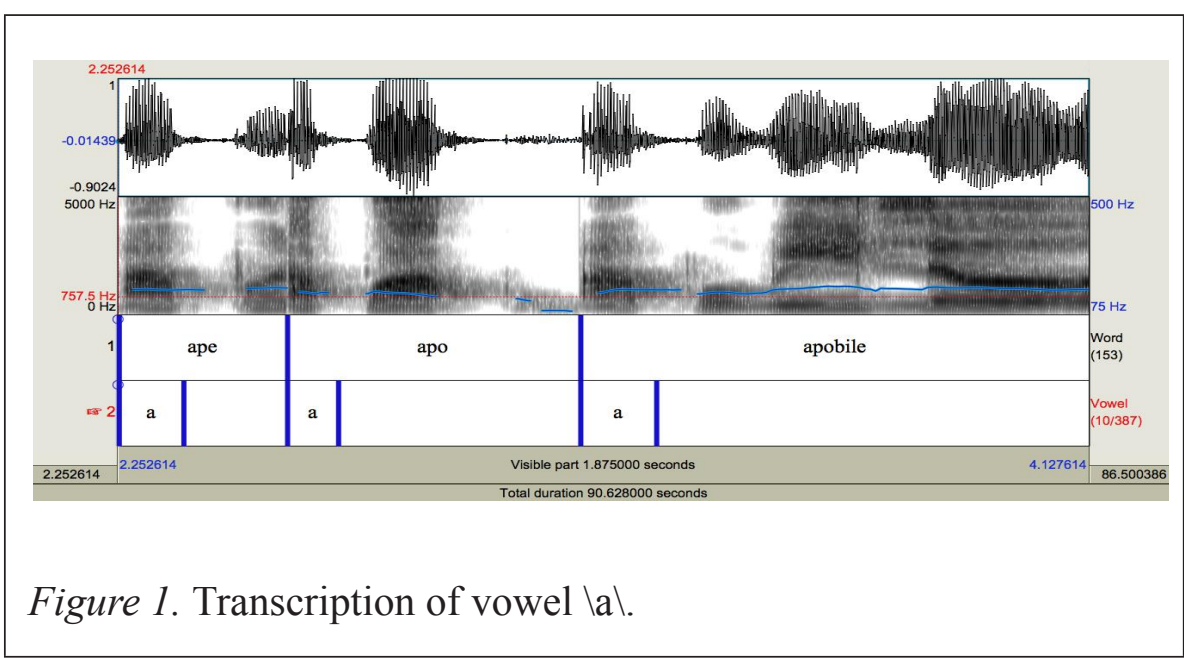

Table 1

Malay vowel dataset

\begin{tabular}{ccccccc}
\hline Vowels & \multicolumn{5}{c}{ No. of Vowels } & \multicolumn{3}{c}{ Duration (s) } \\
\hline & Kelantan & Terengganu & Perlis & Kelantan & Terengganu & Perlis \\
/a/ & 46 & 50 & 29 & 22.99 & 41.23 & 10.22 \\
/e/ & 20 & 6 & 22 & 10.49 & 1.93 & 14.96 \\
/i/ & 28 & 17 & 31 & 16.18 & 21.14 & 4.29 \\
/o/ & 40 & 23 & 13 & 20.86 & 15.01 & 7.67 \\
/u/ & 27 & 29 & 17 & 12.26 & 19.21 & 6.25 \\
/a/ & 35 & 37 & 25 & 21.71 & 27.42 & 12.76 \\
/o/ & 5 & 19 & 5 & 1.41 & 3.46 & 13.47 \\
/E/ & 8 & 2 & 2 & 4.68 & 1.25 & 0.99 \\
Total & 209 & 183 & 144 & 110.58 & 130.65 & 70.61 \\
\hline
\end{tabular}




\section{Extraction of Formant Frequencies}

A total of eight dialect vowels $/ \mathrm{a} /, / \mathrm{e} /, / \mathrm{i} /, / \mathrm{o} /, / \mathrm{u} /, / \mathrm{\partial} /, / \mathrm{o} /$, and $/ \varepsilon /$ were extracted for the district of Kelantan, Perlis and Terengganu. Formant extraction was done using Praat (Boersma et al., 2015) for all the vowels. The standard format setting of Praat was fixed at $5500 \mathrm{~Hz}$ of maximum formant frequency, four numbers of formants, 25 milliseconds of window length, and a dynamic range of $30 \mathrm{~dB}$. Formant frequencies (F1-F4) for each vowels were calculated in Praat using the middle point value of formants for each sample. An example of a spectrogram for the vowel /a/ is illustrated in Figure 2. Each formant (F1F4) are observed in the wideband spectrogram as the darkest bands.

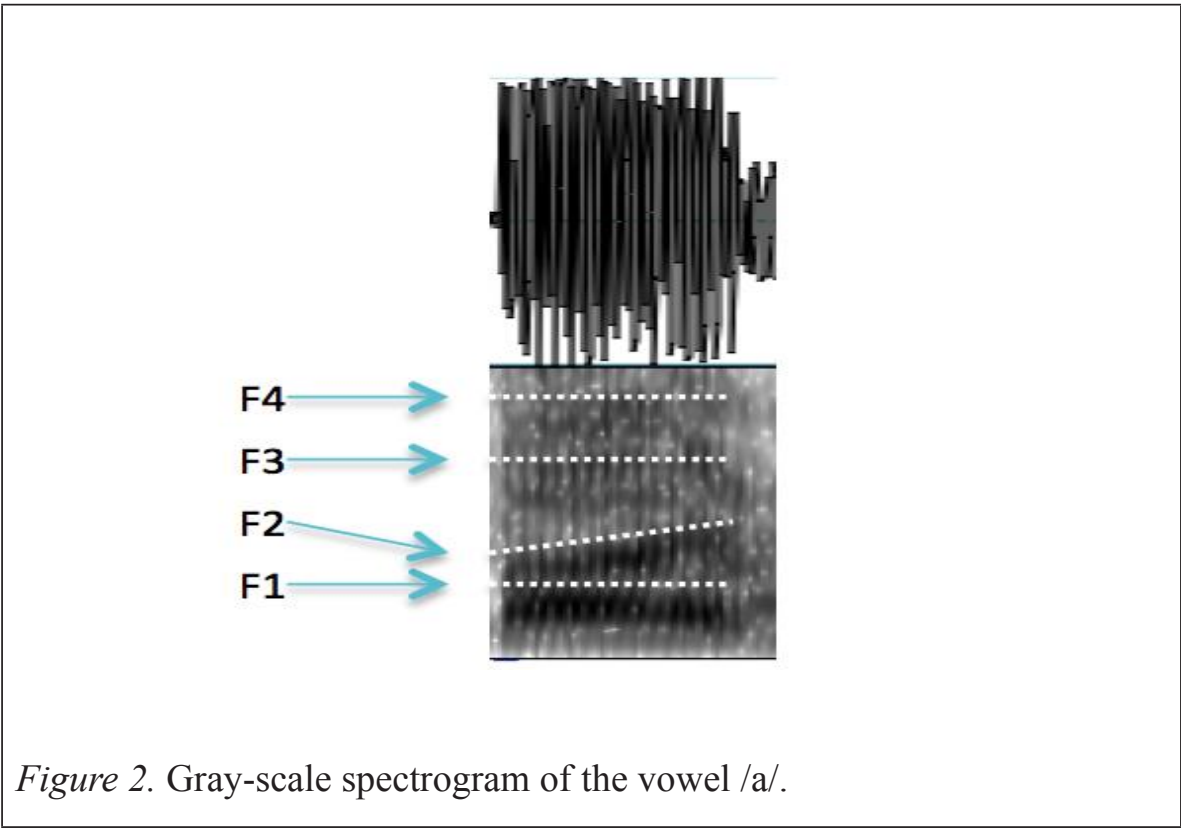

In Figure 3, the four formant frequencies for all 45 vowels of /a/ from the Kelantan dialects were shown. In general, the distribution of each formant of vowel /a/ shown are discriminative. Each of the formant frequencies play a specific role in speech production. The F1 and F2 formants are examined to determine the quality of vowels, and corresponds to the opening or closing of the mouth, and the front or back dimensions of the mouth. F1 is inversely correlated to vowel height; the higher the formant frequency, the lower the vowel height (Ladefoged \& Johnson, 2014). As for F2, the higher the second formant (F2) frequency, the more the frontness of the vowel due to the roundness of the lips. Furthermore, high formant frequencies such as F3 and F4, are a function for high pitch especially in singing. F3 and F4 are 
manipulated by lowering the larynx and elevating the tongue blade. This paper only discusses F3 and F4 briefly as these formants are more a function for the spectral qualities of singing (Wood, 2018).

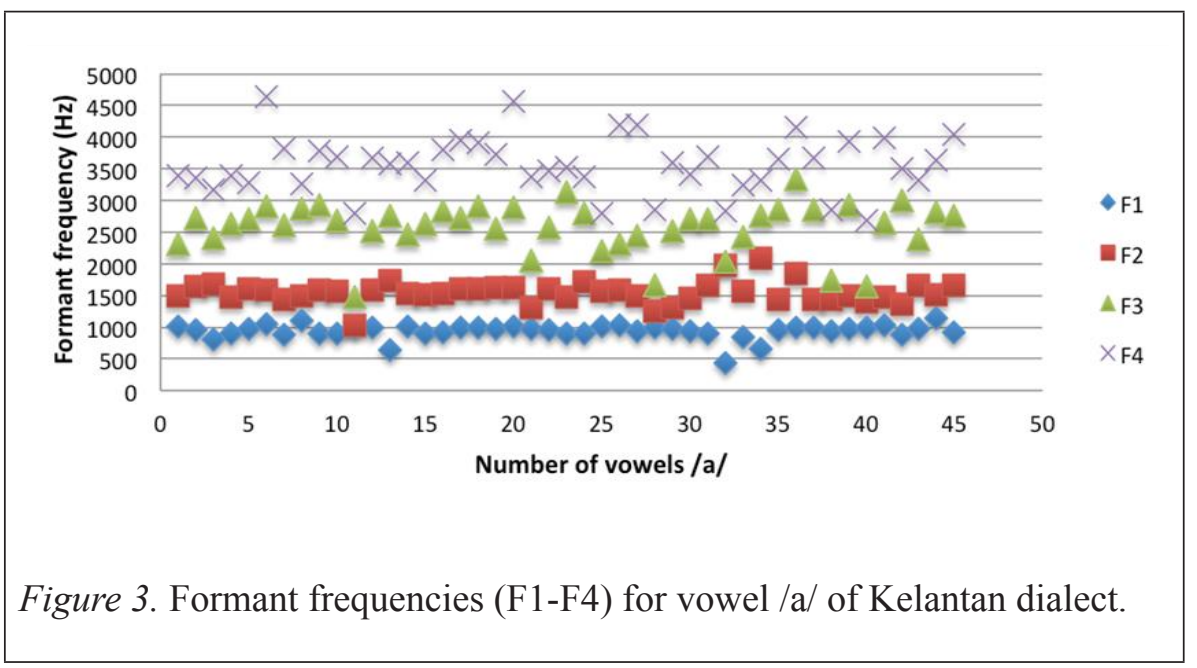

\section{RESULT AND DISCUSSION}

The mean formant frequencies for Malay vowels of Kelantan, Perlis, and Terengganu were calculated and presented in Figure 4. As shown in Figure 4 , the mean formant values (F1-F4) across all vowels in the different dialects of Kelantan, Perlis, and Terengganu are distinct and indicates the differences in pronunciations for most vowels. Figure 4(a) shows the first formant (F1) for all eight vowels from the three districts. F1 is used to determine the close and open position of the mouth during the vowels' production. Although the mean formant values are different for each district, the open and close position of the mouth is relatively the same for all three districts, as observed in the shape of the line graphs. In addition, only the vowels /i/ and /o/ of the Perlis dialect have a slightly different mouth positions, as compared to the Kelantan and Terengganu dialects. The mean formant of F2 for all vowels in all three dialects shown in Figure 4(b) determines the frontness or backness of the mouth during the vowels' pronunciation. The results show that all eight vowels in the Perlis dialects are produced at about the same location in the mouth or at very close locations. The estimates for location is based on the average F2 of all the vowels that is observed as a straight line. On the contrary, the vowels produced by the Terengganu and Kelantan dialects are located in the same positions in the mouth. Since F3 and F4 are not commonly used to describe vowels' production, Figure 4(c) and 4(d) are not discussed. 


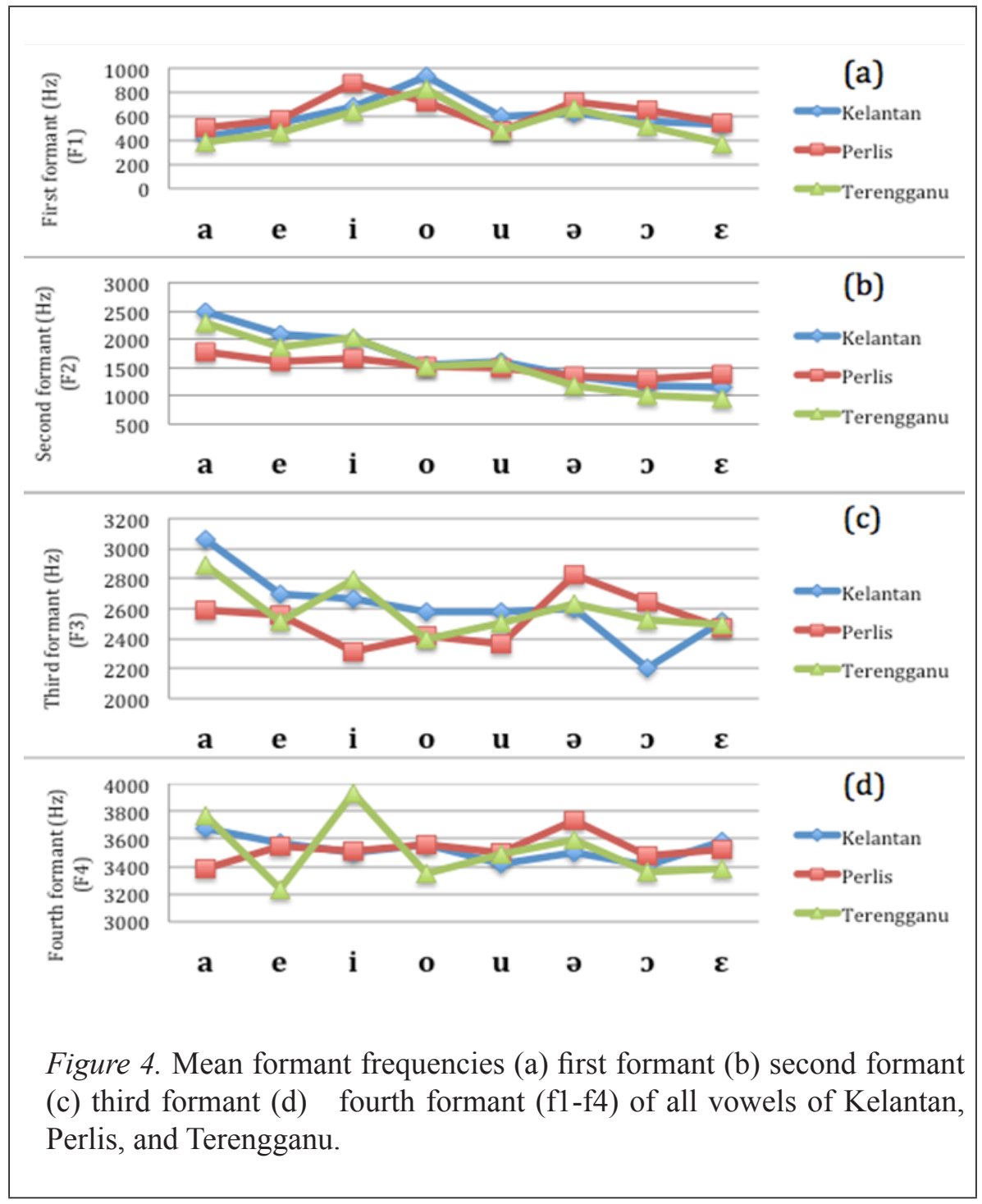

As stated by Amir et al. (2012), F1 and F2 are acknowledged as the main carriers of information that are necessary for vowel identification. Therefore, further analysis of these two formants were carried out. The mean and standard deviation of $\mathrm{F} 1$ and $\mathrm{F} 2$ for the eight vowels $(/ \mathrm{a} /, / \mathrm{e} /, / \mathrm{i} /, / \mathrm{u} /, / \mathrm{\partial} /, / \mathrm{o} /, / \mathrm{\jmath} /, / \varepsilon /)$ from the three dialects are presented in Tables 1 and 2, respectively. Based on the results from Table 1, the Kelantan dialect has the highest average mean of F1 at $612.35 \mathrm{~Hz}$. This implies that the vowels spoken in the Kelantan dialect have a lower vowel height, compared to the dialects of Perlis and Terengganu. The findings suggest that the vowels in the Kelantan dialect are generally produced 
by the lower tongue that causes the openness of the mouth. The vowel /a/ of the Kelantan dialect has the highest F1 at $936.47 \mathrm{~Hz}$. The standard deviations in Table 1 and 2 show the dispersion of the datasets for each vowels, relative to its mean. The low standard deviation indicates that the data points are close to the average, while a high standard deviation indicates that the data points are spread out over a wider range of values. The standard deviation of F1 in Table 1 shows that the Kelantan dialect has a wider range of F1 with a mean of $184.39 \mathrm{~Hz}$, and a high average standard deviation for the vowels $/ \mathrm{u} /$ and $/ \mathrm{\partial} /$ of more than $300 \mathrm{~Hz}$. However, the Terengganu dialect has the lowest average standard deviation mean of $\mathrm{F} 1$ at $90.56 \mathrm{~Hz}$, with the vowel $/ \mathrm{u} /$ having a standard deviation of $\mathrm{F} 1$ at $36.73 \mathrm{~Hz}$.

Table 2

Mean and standard deviation of F1 for all dialects across the vowels

\begin{tabular}{ccccccc}
\hline & \multicolumn{3}{c}{ Mean (Hz) } & \multicolumn{3}{c}{ Standard Deviation (Hz) } \\
\hline & Kelantan & Perlis & Terengganu & Kelantan & Perlis & Terengganu \\
/i/ & 426.60 & 504.54 & 379.19 & 124.50 & 125.40 & 62.98 \\
/e/ & 543.10 & 579.40 & 462.16 & 153.88 & 82.19 & 76.98 \\
/\&/ & 675.74 & 597.21 & 759.49 & 87.39 & 79.62 & 169.80 \\
/a/ & 936.47 & 714.18 & 831.05 & 117.82 & 155.34 & 112.51 \\
/ə/ & 597.23 & 479.73 & 479.73 & 319.74 & 110.44 & 114.73 \\
/ / & 620.40 & 721.44 & 661.83 & 188.56 & 123.28 & 83.55 \\
/o/ & 561.98 & 654.68 & 514.07 & 155.15 & 119.56 & 67.21 \\
/u/ & 537.27 & 542.50 & 376.40 & 328.11 & 75.79 & 36.73 \\
Mean & 612.35 & 599.21 & 557.99 & 184.39 & 108.95 & 90.56 \\
\hline
\end{tabular}

The observation on the second formant (F2) shows that the vowels /a/ and /a/ does not have a significant difference of F2 between the three dialects. Overall, the mean of F2 between the three dialects do not show much difference. However, vowels / / / and / $\mathrm{u} /$ of the Kelantan dialects; and vowel /e/ of Terengganu dialect show a high standard deviation of $549.30 \mathrm{~Hz}, 418.13 \mathrm{~Hz}$, and $478.90 \mathrm{~Hz}$ respectively. This suggests that the pronunciations for vowels /u/, /\&/ from Kelantan and vowel /e/ from Terengganu are widely spread out from the mean value, and indicates the versatility for the pronunciation of the vowels. 
Table 3

Mean and standard deviation of F2 for all dialects across the vowels

\begin{tabular}{ccccccc}
\hline & \multicolumn{3}{c}{ Mean (Hz) } & \multicolumn{3}{c}{ Standard Deviation (Hz) } \\
\hline Kelantan & Perlis & Terengganu & Kelantan & Perlis & Terengganu \\
/i/ & 2499.36 & 1779.34 & 2297.84 & 275.49 & 159.03 & 375.76 \\
/e/ & 2082.72 & 1615.38 & 1871.51 & 309.74 & 305.28 & 478.90 \\
/ / / & 2003.49 & 1669.60 & 2044.0 & 249.49 & 91.42 & 264.74 \\
/a/ & 1551.45 & 1534.74 & 1529.43 & 173.25 & 299.66 & 300.93 \\
/o/ & 1593.98 & 1505.98 & 1574.19 & 549.30 & 257.88 & 329.77 \\
/o/ & 1363.68 & 1363.20 & 1186.33 & 255.13 & 289.23 & 186.69 \\
/u/ & 1180.44 & 1300.90 & 1015.51 & 279.04 & 129.04 & 104.61 \\
Mean & 1152.66 & 1371.52 & 948.563 & 418.13 & 278.57 & 266.38 \\
\hline
\end{tabular}

\section{Vowel Diagram of Kelantan, Perlis and Terengganu Dialects}

Based on the mean frequency of F1 and F2, the vowel diagram for the eight vowels (/a/, /e/, /i/, /u/, /ə/, /o/, / /, / / / ) of the Kelantan, Perlis and Terengganu dialects was plotted, as illustrated in Figure 5. The vowel diagram represents the speech articulatory or physical space inside the mouth of the human body. The first formant (F1) represents the height of the tongue body. If the vowel has a high first formant, the low tongue body was used to produce it. This type of vowel is known as 'low vowel'. Meanwhile, a low first formant indicates that the high tongue body was used, and this type of vowel is known as 'high vowel'. The value of the second formant represents the frontness or backness of the tongue body when articulating a vowel. The vowel with a high second formant implies that the vowel was pronounced at the front of the tongue body, and is known as the 'front vowel'. Subsequently, a vowel with a low second formant implies that the vowel was pronounced at the back of the tongue body, and this is known as 'back vowel'.

Overall, the vowel pronunciations for Kelantan, Perlis and Terengganu dialects comply with the International Phonetic Alphabet (IPA) vowel diagram. For example, the vowel $/ \mathrm{i}$ / for all three dialects are pronounced at the front of the mouth and is positioned on the roof of the mouth (i.e., close). This finding is in 


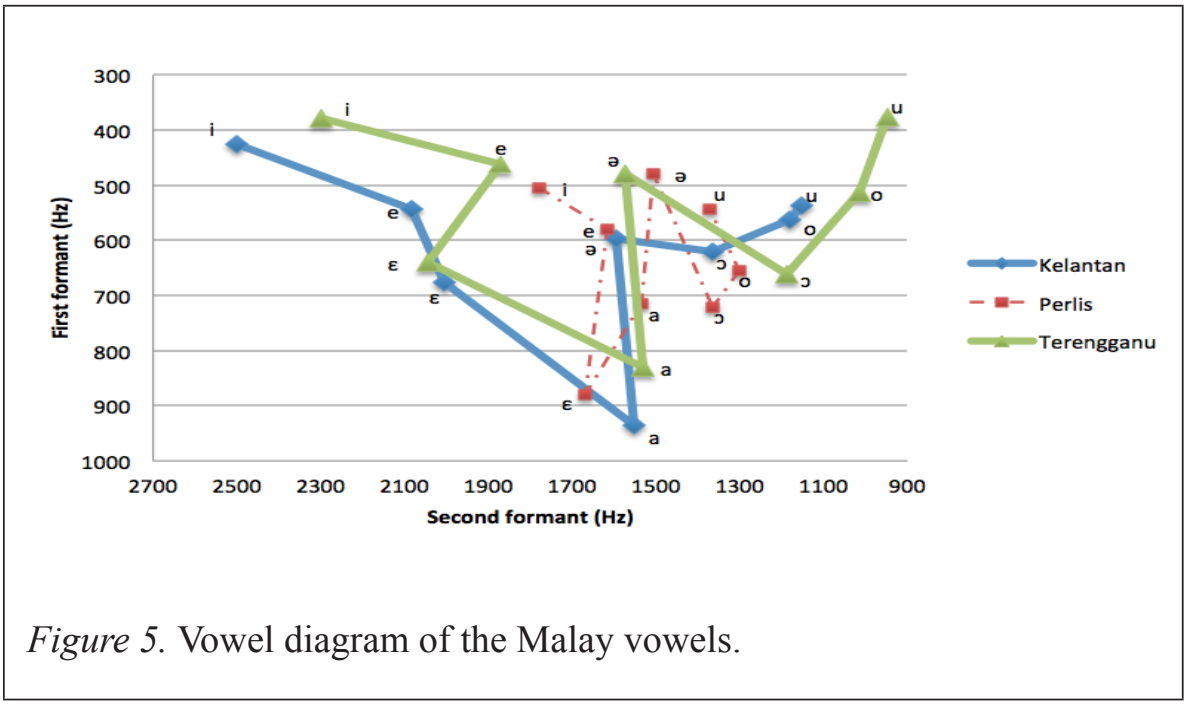

accordance with the studies by (Omar, 1988) and (Teoh, 1984). Furthermore, it is noted that the vowels in the Perlis dialect have a smaller range of F1 and F2, compared to vowels spoken in Kelantan and Terengganu dialects. This indicates that the degree of openness and closeness of the mouth during Perlis dialect vowel production is smaller compared to Kelantan and Terengganu. Moreover, the Perlis dialect has a smaller degree of frontness and backness that is based on the narrow range of F2 when articulating vowels. As stated earlier, Kelantan and Terengganu dialects have a broader range of the second formant as compared to Perlis. This suggests that the Kelantan and Terengganu dialects uses the front and back of the tongue body more often than in the Perlis dialect. Furthermore, the vowels of Terengganu dialects have the lowest F1 for all vowels except /a/, compared to Perlis and Kelantan. This implies that the Terengganu vowels are mostly high vowels that utilises the high tongue body, which takes a longer duration (Toivonen, Blumenfeld, Gormley, Hoiting, Logan, Ramlakhan, \& Stone, 2015) for its articulation. These high vowels may have influenced the 'dragging' sound dialect of the Terengganu district. Further investigation should be conducted to investigate whether this generalization is due to phonetic or phonological. The vowels $/ \varepsilon /$ for the Kelantan and Terengganu dialects are closely located in the mouth and indicates that the vowel $/ \mathcal{\varepsilon} /$ is pronounced similarly. The same can be said for vowel /a/ of Perlis and Terengganu dialects.

\section{First and Second Formants of Kelantan, Perlis and Terengganu Dialects}

Table 4 and Table 5 classifies the eight Malay vowel dialects based on its first formant and second formants. As observed in Table 4, each dialect has 
a unique mean of F1 which defines the way the vowels are pronounced. For example, the close vowels of the Terengganu dialects range between $376.41 \mathrm{~Hz}$ to $379.20 \mathrm{~Hz}$. As for the Perlis vowels dialect, these vowels range between $504.54 \mathrm{~Hz}$ to $542.51 \mathrm{~Hz}$. The distance between each dialect was calculated using the Euclidean metric to understand the similarities that are present. The Euclidean distance of mean F1 between the Perlis and Terengganu dialects is $346.93 \mathrm{~Hz}$; the distance between Perlis and Kelantan is $309.21 \mathrm{~Hz}$; and the distance between Terengganu and Kelantan is $243.94 \mathrm{~Hz}$. The distance results show that the Terengganu and Kelantan dialects are mostly similar with regards to the openness and closeness of the mouth during vowel pronunciations. On the other hand, the Perlis and Terengganu dialects are the most dissimilar dialects, based on the Euclidean measure.

Table 4

Openness and closeness of the mouth of Malay vowels

\begin{tabular}{ccccc}
\hline & & \multicolumn{3}{c}{ Mean $(\mathrm{Hz})$} \\
Vowel Type & Vowel & Kelantan & Perlis & Terengganu \\
\hline Close & /i/ & 426.61 & 504.54 & 379.20 \\
& /u/ & 537.28 & 542.51 & 376.41 \\
Close-mid & /e/ & 543.10 & 579.40 & 462.16 \\
& $/$ o / & 561.98 & 654.69 & 514.08 \\
Open-mid & $/ \varepsilon /$ & 675.74 & 597.21 & 759.49 \\
& $/$ ə / & 597.23 & 479.74 & 479.74 \\
& $/ \mathrm{a} /$ & 620.40 & 721.45 & 661.84 \\
Open & /a / & 936.48 & 714.18 & 831.05 \\
\hline
\end{tabular}

Table 5 records the second formant of the vowels for all three dialects. The front vowels for the Kelantan dialect range between $1551.46 \mathrm{~Hz}$ to $2499.36 \mathrm{~Hz}$, while the Terengganu front vowels range between 1529.43 to $2297.85 \mathrm{~Hz}$. On the other hand, the front vowels of Perlis range between $1534.74 \mathrm{~Hz}$ to $1779.34 \mathrm{~Hz}$. The distance of mean F2 between the three dialects were calculated using the Euclidean metrics, and the results are as follows: Perlis and Terengganu dialects resulted in $878.04 \mathrm{~Hz}$; Perlis and Kelantan is $958.52 \mathrm{~Hz}$; while Terengganu and Kelantan is $433.64 \mathrm{~Hz}$. The distance measure results show that vowels pronounced in the Kelantan and Terengganu dialects are mostly similar compared to the vowels pronounced between Perlis and 
Terengganu, and Perlis and Kelantan. Based on these findings, this paper concludes that the vowel pronunciation for the Kelantan and Terengganu dialects are significantly similar and are positioned at the tongue and openness of the mouth.

Table 5

Frontness and backness of the mouth of Malay vowels

\begin{tabular}{ccccc}
\hline \multirow{2}{*}{ Vowel Type } & Vowel & Kelantan & Perlis & Terengganu \\
\hline \multirow{2}{*}{ Front } & /a/ & 1551.46 & 1534.74 & 1529.43 \\
& $/ \mathrm{e} /$ & 2082.73 & 1615.39 & 1871.52 \\
& $/ \mathrm{i} /$ & 2499.36 & 1779.34 & 2297.85 \\
\multirow{2}{*}{ Central } & $/ \mathrm{E} /$ & 2003.50 & 1669.60 & 2044.01 \\
& $/ \mathrm{a} /$ & 1593.98 & 1505.99 & 1574.19 \\
& $/ \mathrm{o} /$ & 1180.44 & 1300.90 & 1015.51 \\
Back & $/ \mathrm{u} /$ & 1152.67 & 1371.53 & 948.56 \\
& $/ \mathrm{J} /$ & 1363.68 & 1363.20 & 1186.33 \\
\hline
\end{tabular}

\section{CONCLUSION}

This paper investigates and documents the vowels of the Malay dialects for Kelantan, Perlis, and Terengganu, using formant frequencies. Although similar works have been conducted for the Kedah dialect in Afiqah (2017), the spoken data used in the study were obtained from read speeches and therefore, produced conflicting results. In this paper, the Malay vowels of spontaneous speeches from Kelantan, Perlis, and Terengganu were investigated. The first and second formants of eight vowels, (/a/, /e/, /i/, /u/, /ə/, /o/, /o/, / / /) were analyzed to objectively measure the openness and closeness of the mouth, and the frontness and backness of the pronunciation. The vowel diagram of the Malay vowels of Perlis, Kelantan, and Terengganu was charted to highlight the differences and similarities. The vowel diagram constructed is the main contribution of this paper. Based on the vowel chart, the pronunciation of the Malay vowels from Perlis, Kelantan, and Terengganu comply with the IPA standard. The mean F1 and F2 for all eight vowels are documented for future references as research or as an educational tool for language learning. 
In comparison to vowels of the Perlis dialect, the Terengganu and Kelantan vowels are similar based on the wider range of formants produced. However, further research is required to investigate the correlation between duration and vowel height, and to conduct a comprehensive analysis on formant frequencies for a better understanding of the different dialects in Malaysia.

\section{ACKNOWLEDGMENT}

The study was funded by the Ministry of Education and Research Institute of Research, Management and Innovation, Universiti Teknologi MARA for the funding received through the Fundamental Research Grant Scheme, 600RMI/FRGS 5/3 (019/2017).

\section{REFERENCES}

Afiqah Jazmin, A. (2017). An acoustics study of the monophthongs of Kedah Malay. Doctoral dissertation, University of Malaya.

Amir, N., Tzenker, O., Amir, O., \& Rosenhouse, J. (2012). Quantifying vowel characteristics in hebrew and Arabic, In Speech Precessing Conference (pp. 37-43).

Asmah, H. O. (1988). Susur galur bahasa Melayu. Kuala Lumpur: Dewan Bahasa dan Pustaka.

Boersma, P., David, W., \& Heuven, V. (2015). Praat, doing phonetics by computer. Retrieved May 20, 2001, from http://www.praat.org/

Collins, E. F., \& Bahar, E. (2000). To know shame: Malu and its uses in Malay societies. In Crossroads: An Interdisciplinary Journal of Southeast Asian Studies, 14(1), 35-69. Center for Southeast Asian Studies Northern Illinois University.

Collins, J. T. (1989). Malay dialect research in Malaysia: The Issue of Perspective. Journal of the Humanities and Social Sciences of Southeast Asia and Oceania, 145(2), 2-3.

Encyclopedia Britannica. (2018). Retrieved September 3, 2018, from https:// www.britannica.com/topic/ Malay-language

Ikkunointi. (2016). Windowing. Retrieved from http://www.cs.tut.fi/kurssit/ SGN-4010/ikkunointi_en.pdf

Ladefoged, P., \& Johnson, K. (2014). A course in phonetics ( $7^{\text {th }}$ ed.). Boston: Cengage Learning.

O'Grady, W., \& Archibald, J. (2015). Contemporary linguistic analysis: An introduction. Pearson Canada. 
Omar, A. (1985). Patterns of language communication in Malaysia. Southeast Asian Journal of Social Science,13(1), 19-28.

Omar, A. H. (1988). Susur galur bahasa Melayu. Kuala Lumpur: Dewan Bahasa dan Pustaka.

Podder, P., Khan, Zaman, T., \& Haque Khan, M. (2014). Comparative performance analysis of hamming, hanning and blackman window. International Journal of Computer Applications, 96(18), 1-7.

Teoh, B. S. (1994). The sound system of Malay revisited. Kuala Lumpur: Dewan Bahasa dan Pustaka.

Ting, H. N., Chia, S. Y., Kim, K. S., Sim, S. L., \& Abdul Hamid, B. (2011a). Vocal fundamental frequency and perturbation measurements of vowels by normal Malaysian Chinese adults. Journal of Voice, 25(6), e311e317.

Ting, H. N., Chia, S. Y., Abdul Hamid, B., \& Mukari, S. Z. M. S. (2011b). Acoustic characteristics of vowels by normal Malaysian Malay young adults. Journal of Voice, 25(6), e305-e309.

Ting, H.-N., Zourmand, A., Chia, S.-Y., Yong, B. F., \& Abdul Hamid, B. (2012a). Formant frequencies of Malay vowels produced by Malay children aged between 7 and 12 years. Journal of Voice, 26(5), 664. e1-664.e6.

Ting, H. N., Chia, S. Y., Manap, H. H., Ho, A. H., Tiu, K. Y., \& Abdul Hamid, B. (2012b). Fundamental frequency and perturbation measures of sustained vowels in Malaysian Malay children between 7 and 12 years old. Journal of Voice, 26(4), 425-430.

Toivonen, I., Blumenfeld, L., Gormley, A., Hoiting, L., Logan, J., Ramlakhan, N., \& Stone, A. (2015). Vowel height and duration. In West Coast Conference on Formal Linguistics, 32, 64-71.

Wardhaugh, R. (2011). An introduction to sociolinguistics (Vol. 28). United Kingdom: John Wiley \& Sons.

Wood, S. (2018). What are formants? Beginners guide to praat. Retrieved September 15, 2018, from http://person2.sol.lu.se/SidneyWood/praate/ whatform.html

Yusuf, Y. Q. (2013). A comparative study of vowels in the acehnese language spoken in Kedah, Malaysia and Aceh, Indonesia. Universiti Malaya.

Zourmand, A., Mirhassani, S. M., Ting, H. N., Bux, S. I., Ng, K. H., Bilgen, M., \& Jalaludin, M. A. (2014). A magnetic resonance imaging study on the articulatory and acoustic speech parameters of Malay vowels. BioMedical Engineering Online, 13(103). 